\title{
Sulfate and chromate increased each other's uptake and translocation in As-hyperaccumulator Pteris vittata
}

\author{
Letúzia M. de Oliveira ${ }^{\mathrm{a}, \mathrm{b}}$, Julia Gress ${ }^{\mathrm{b}}$, Jaysankar De ${ }^{\mathrm{b}}$, Bala Rathinasabapathi ${ }^{\mathrm{c}}$, \\ Giuliano Marchi ${ }^{\mathrm{d}}$, Yanshan Chen ${ }^{\mathrm{a}, *}$, Lena Q. Ma ${ }^{\mathrm{a}, \mathrm{b},{ }^{\mathrm{b}}}$, \\ a State Key Laboratory of Pollution Control and Resource Reuse, School of the Environment, Nanjing University, Jiangsu 210046, China \\ ${ }^{\mathrm{b}}$ Soil and Water Science Department, University of Florida, Gainesville, FL 32611, USA \\ ${ }^{\mathrm{c}}$ Horticultural Sciences Department, University of Florida, Gainesville, Florida 32611, United States \\ ${ }^{\mathrm{d}}$ Researcher at Embrapa Cerrados, Rod. BR 020, km 18, CP 08223, CEP 73310-970 Planaltina, DF, Brazil
}

\section{H I G H L I G H T S}

- CrVI and sulfate uptake by Ashyperaccumulator P.vittata was investigated.

- CrVI and sulfate enhanced each other's uptake by $P$. vittata.

- P. vittata was efficient in CrVI accumulation in the roots with little translocation.

- Though CrVI was supplied, Cr was mainly present as CrIII in the biomass.

- CrVI was probably not taken up by $P$. vittata via sulfate transporters.

\section{A R T I C L E I N F O}

\section{Article history:}

Received 22 July 2015

Received in revised form

17 November 2015

Accepted 23 December 2015

Available online $\mathrm{xxx}$

Handling Editor: Martine Leermakers

\section{Keywords:}

Chromium

Sulfate

Pteris vittata

Uptake

Translocation

Speciation

\section{G R A P H I C A L A B S T R A C T}

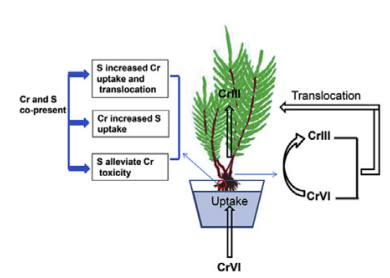

\begin{abstract}
A B S T R A C T
We investigated the effects of chromate (CrVI) and sulfate on their uptake and translocation in Ashyperaccumulator Pteris vittata. Plants were exposed to 1) $0.1 \mathrm{mM} \mathrm{CrVI}$ and $0,0.25,1.25$ or $2.5 \mathrm{mM}$ sulfate or 2) $0.25 \mathrm{mM}$ sulfate and $0,0.5,2.5$ or $5.0 \mathrm{mM}$ CrVI for $1 \mathrm{~d}$ in hydroponics. P. vittata accumulated 26 and $1261 \mathrm{mg} \mathrm{kg}^{-1} \mathrm{Cr}$ in the fronds and roots at $\mathrm{CrVI}_{0.1}$, and 2197 and $1589 \mathrm{mg} \mathrm{kg}^{-1} \mathrm{~S}$ in the fronds and roots at $\mathrm{S}_{0.25}$. Increasing sulfate concentrations increased $\mathrm{Cr}$ root concentrations by $16-66 \%$ and helped CrVI reduction to CrIII whereas increasing CrVI concentrations increased frond sulfate concentrations by $3-27 \%$. Increasing sulfate concentrations enhanced TBARS concentrations in the biomass, indicating oxidative stress caused lipid peroxidation in plant cell membranes. However, addition of $0.25-2.5 \mathrm{mM}$ sulfate alleviated CrVI's toxic effects and decreased TBARS from 23.5 to $9.46-12.3 \mu \mathrm{mol} \mathrm{g}^{-1}$ FW. Though CrVI was supplied, $78-96 \%$ of CrIII was in the biomass, indicating efficient CrVI reduction to CrIII by $P$. vittata. The data indicated the amazing ability of $P$. vittata in $\mathrm{Cr}$ uptake at $289 \mathrm{mg} \mathrm{kg}^{-1} \mathrm{~h}^{-1}$ with little translocation to the fronds. These results indicated that $P$. vittata had potential in $\mathrm{Cr}$ phytoremediation in contaminated sites but further studies are needed to evaluate this potential. The facts that CrVI and sulfate helped each other in uptake by $P$. vittata suggest that CrVI was not competing with sulfate uptake in $P$. vittata. However, the mechanisms of how sulfate and CrVI enhance each other's accumulation in $P$. vittata need further investigation.
\end{abstract}

Published by Elsevier Ltd.

\footnotetext{
* Corresponding author. State Key Laboratory of Pollution Control and Resource Reuse, School of the Environment, Nanjing University, Jiangsu 210046, China.

E-mail address: lqma@ufl.edu (L.Q. Ma).
} 


\section{Introduction}

Chromium $(\mathrm{Cr})$ has gained environmental importance due to its toxic effects on living organisms. Though it occurs naturally in soils, anthropogenic activities are major sources of $\mathrm{Cr}$ contamination, including pigment-electroplating industries, mining processes and fertilizer applications (Kristine et al., 2013). The health effects of human exposure to $\mathrm{Cr}$ range from dermatitis and dermatosis to various cancers. $\mathrm{Cr}$ exposure is also associated with decreases in plant growth and changes in plant morphology (López-Bucio et al., 2014).

Both hexavalent ( $\mathrm{CrVI}$ ) and trivalent $\mathrm{Cr}$ (CrIII) can be found in soils, however, they differ significantly in toxicity. While CrVI is mobile and usually present as chromate $\left(\mathrm{CrO}_{4}^{-2}\right)$ or dichromate $\left(\mathrm{Cr}_{2} \mathrm{O}_{7}^{-2}\right)$ in soils, $\mathrm{CrIII}$ is often present as oxides and is less mobile. In humans, CrVI is classified as a carcinogen of Group A (ATSDR, 2012) while CrIII is an essential nutrient (Dimitroula et al., 2015). The USEPA limit for total $\mathrm{Cr}$ in potable water and discharge to surface water is 0.05 and $0.1 \mathrm{mg} \mathrm{L}^{-1}$, respectively (EPA, 1990). The differences in Cr's behaviors make it important to understand $\mathrm{Cr}$ speciation in the environment. Unlike $\mathrm{Cr}$, sulfur is an essential macronutrient for plant growth, often making up $0.5-1.0 \mathrm{~g} \mathrm{~kg}^{-1}$ of plant's biomass (Marschner, 2012). Its main form for plant uptake is sulfate, which is taken up by the roots through sulfate transporters (Marschner, 2012).

Due to CrVI's toxicity, the impact of $\mathrm{Cr}$ on plants has been a subject of extensive study. Unlike sulfur, $\mathrm{Cr}$ is not an essential element, so plants would not have likely developed a specific system for its uptake (Shanker et al., 2005; Oliveira et al., 2012). Plant uptake of CrIII is a passive process with no energy being required (Shanker et al., 2005). However, CrVI is likely taken up by plants through an active mechanism via sulfate or phosphate transporter because CrVI structurally resembles sulfate and phosphate (Kim et al., 2006). Competitive uptake between sulfate and CrVI has been shown in plants possibly because CrVI uses sulfate transporter due to their structural similarity (Ramírez-Díaz et al., 2008). It has been shown that sulfate inhibits CrVI uptake in wheat and barley (Kleinman and Cogliatti, 1997). However, other researchers reported that sulfate has no effect on plant CrVI uptake (Zakaria et al., 2007). In addition, CrVI also inhibits sulfate uptake although a general effect of CrVI on active membrane transport has been excluded (Schiavon et al., 2007). However, CrVI uptake was stimulated after pre-cultivation of Zea mays plants in sulfate-limited nutrient media, suggesting that other transporters could be involved in CrVI uptake in plants (Schiavon et al., 2007). In Pteris vittata plants, CrVI inhibited phosphate uptake when CrVI was supplied after 1-d exposure (de Oliveira et al., 2015). Similarly, Qian et al. (2013) found that increasing P concentration in the medium alleviated $\mathrm{Cr}$ toxicity in alga Chlorella vulgaris by decreasing its $\mathrm{Cr}$ absorption. The authors attributed the reduced metal toxicity to decreased $\mathrm{Cr}$ absorption under high-P conditions.

$P$. vittata is efficient in arsenic (As) accumulation (Ma et al., 2001) and can also accumulate large amounts of $\mathrm{Cr}$ in the roots (de Oliveira et al., 2014; de Oliveira et al., 2015; Sridhar et al., 2011; Kalve et al., 2011). Some researchers speculate that CrVI is probably taken up by $P$. vittata via sulfate transporters (Shiavon et al., 2007, 2012). However, little is known about the impact of sulfate on CrVI uptake and translocation in P. vittata. The overall objective of this study was to evaluate the impact of sulfate (essential nutrient) and CrVI (toxic element) on each other's uptake and translocation in $P$. vittata, following exposure to CrVI and sulfate at different concentrations for $1 \mathrm{~d}$ in aerated hydroponic solutions. Our objectives were to 1 ) investigate the effects of sulfate and CrVI on each other's uptake and translocation in $P$. vittata, and 2) determine CrVI speciation in PV fronds and roots. Knowledge of how $P$. vittata takes up and transports $\mathrm{Cr}$ provides insight into $\mathrm{Cr}$ uptake in other plants.

\section{Material and methods}

\subsection{Plant material and growth conditions}

Six-month old $P$. vittata plants of uniform size with 4-5 fronds were cultivated in our laboratory. The plants were acclimatized in 0.2-strength Hoagland solution (HS) at $\mathrm{pH} 5.7$ with $1 \mathrm{mM}$ $\mathrm{KOH}-\mathrm{MES}$ buffer for 4 weeks under continuous aeration. The acclimated plants were transferred to $1 \mathrm{~L}$ opaque containers containing S-free $0.2 \mathrm{X}$ HS for 1 week. The water loss via transpiration was replenished by frequent additions of deionized water. Plants were then transferred to $0.2 \mathrm{X} \mathrm{HS}$, which were spiked with different concentrations of $\mathrm{CrVI}$ as $\mathrm{K}_{2} \mathrm{Cr}_{2} \mathrm{O}_{7}$ and sulfate as $\mathrm{Na}_{2} \mathrm{SO}_{4}$, specifically 1) $0.25 \mathrm{mM}$ sulfate and $0,0.5,2.5$ or $5.0 \mathrm{mM} \mathrm{CrVI}$ or 2) $0.1 \mathrm{mM} \mathrm{CrVI}$ and $0,0.25,1.25$ or $2.5 \mathrm{mM}$ sulfate. They are referred to as $\mathrm{CrVI}_{0.5}$, $\mathrm{CrVI}_{2.5}$, or $\mathrm{CrVI}_{5.0}$, and $\mathrm{S}_{0.25}, \mathrm{~S}_{1.25}$, or $\mathrm{S}_{2.5}$. CrIII as $\mathrm{Cr}\left(\mathrm{NO}_{3}\right)_{3} 9 \mathrm{H}_{2} \mathrm{O}$ was tested with $0.1 \mathrm{mM}$ CrIII and 0 or $1.25 \mathrm{mM}$ sulfate. In addition, we also tested the $\mathrm{Cr}$ uptake by another fern Adiantum capillus, which was grown for $1 \mathrm{~d}$ in 0.2 -strength $\mathrm{HS}$ containing $0.25 \mathrm{mM}$ sulfate and $0,0.5,2.5$ or $5.0 \mathrm{mM}$ CrVI.

The plants were kept in a controlled environment with $8 \mathrm{~h}$ photoperiods at light intensity of $350 \mu \mathrm{mol} \mathrm{m}{ }^{-2} \mathrm{~s}^{-1}, 28 / 23{ }^{\circ} \mathrm{C}$ day/ night temperature, and 60-70\% relative humidity. Plants were harvested $1 \mathrm{~d}$ after the treatments.

\subsection{Plant tissues analysis}

Following 1 day exposure to CrVI and sulfate, the $P$. vittata plants were separated into aboveground (fronds) and belowground (roots and rhizomes) biomass. To remove sorbed $\mathrm{Cr}$ from the roots, $P$. vittata roots were washed with distilled water, ice-cold phosphate buffer $\left(1 \mathrm{mM} \mathrm{Na}_{2} \mathrm{HPO}_{4}, 10 \mathrm{mM}\right.$ MES and $0.5 \mathrm{mM} \mathrm{Ca}\left(\mathrm{NO}_{3}\right)_{2}, \mathrm{pH}$ 5.7), and again with distilled water.

Oven-dried $\left(65^{\circ} \mathrm{C}\right.$ for 2 days) samples were digested with $\mathrm{HNO}_{3}$ and $\mathrm{H}_{2} \mathrm{O}_{2}$ for $\mathrm{Cr}$, sulfur ( $\mathrm{S}$ ) and potassium (K) analysis on a hot block digester (Environmental Express, Mt. Pleasant, SC) using USEPA Method 3050B (de Oliveira et al., 2015). Total Cr, S and K concentrations in digested solution were analyzed by inductively coupled plasma-mass spectrometry (ICP-MS Perkin-Elmer Corp., Norwalk, $\mathrm{CT}$ ). Internal standard has been used and standard solution at $20 \mu \mathrm{g} \mathrm{L}^{-1} \mathrm{Cr}$ was measured every 20 samples to monitor the stability of ICP-MS. To determine the amount of $\mathrm{Cr}$ precipitated on $P$. vittata root surfaces, plant roots $(\sim 0.2 \mathrm{~g})$ were washed in $50 \mathrm{ml}$ $1: 1 \mathrm{v} / \mathrm{v} \mathrm{HNO}_{3}$ and water for $20 \mathrm{~min}$ and the $\mathrm{Cr}$ concentrations in the supernatant was determined using ICP-MS.

\subsection{Cr speciation in plant and Hoagland solution}

In this study, a modified method of alkaline digestion based on USEPA Method 3060A (US Environmental Protection Agency, 1995) was employed to extract CrVI in plants. Briefly, $\sim 0.20 \mathrm{~g}$ of dry biomass was transferred into a $100 \mathrm{ml}$ glass beaker with $20 \mathrm{ml}$ of $0.1 \mathrm{M} \mathrm{Na}_{2} \mathrm{CO}_{3}$ and boiled on a hot-plate for $10 \mathrm{~min}$ (Khakhathi et al., 2011). After cooling, samples were filtered through Whatman no.1 filter paper and diluted to a volume of $50 \mathrm{ml}$ with deionized water. The solution was used to determine CrVI by ICP-MS. During the extraction, $\mathrm{CrVI}$ was solubilized by $\mathrm{Na}_{2} \mathrm{CO}_{3}$ solution to form $\mathrm{Na}_{2} \mathrm{CrO}_{4}$ while CrIII species formed insoluble hydroxides or carbonates.

The accuracy of $\mathrm{Cr}$ speciation using the procedure was determined by spiking $10 \mathrm{mg} \mathrm{L}^{-1}$ CrIII or CrVI to $\mathrm{Cr}$-free plant extract. There was no change in redox status since the recovery of the 
spiked $\mathrm{Cr}$ was $100 \pm 5 \%$ (data not shown). In addition, Standard Reference Material 1547 (peach leaves) from the National Institute of Science and Technology (Gaithersburg, MD) and appropriate reagent blanks, internal standards and spikes were used to ensure method accuracy and precision.

In addition to $\mathrm{Cr}$ speciation in plant biomass, CrVI concentrations in $0.2 \mathrm{X}$ HS were measured using a colorimetric reagent specific for CrVI, 1,5-diphenylcarbazide, which was dissolved in $0.05 \%$ acetone (Eaton et al., 1995). Absorbance was measured with spectrophotometer (UVI1800U, Shimadzu Corp., Columbia, MD) at $540 \mathrm{~nm}$, and CrVI concentration was calculated with a standard curve prepared using a series of CrVI dilutions (1-25 $\mathrm{mg} \mathrm{L}^{-1}$ ). Furthermore, metal speciation in solution was performed using Visual MINTEQ3 (Gustafsson, 2011).

\subsection{Lipid peroxidation in plant biomass}

The amount of thiobarbituric acid reactive substances (TBARS) was determined following Groppa et al. (2001) to determine the impact of $\mathrm{Cr}$ on lipid peroxidation in P. vittata fronds. About $0.3 \mathrm{~g}$ of frozen-tissues was cut into small pieces and homogenized, using a cold mortar and pestle in ice bath with $1.5 \mathrm{ml}$ of $5 \%(\mathrm{wt} / \mathrm{v})$ trichloroacetic acid (TCA) solution. The homogenate was transferred into fresh tubes and centrifuged at $10,000 \times \mathrm{g}$ for $10 \mathrm{~min}$ at room temperature. To $1 \mathrm{ml}$ of the aliquot of the supernatant, $1 \mathrm{ml}$ of $20 \%$ $(\mathrm{w} / \mathrm{v})$ TCA containing $0.5 \%(\mathrm{w} / \mathrm{v})$ TBA were added. The mixture was heated at $95{ }^{\circ} \mathrm{C}$ for $30 \mathrm{~min}$ and then quickly cooled on ice. The absorbance of the supernatant was measured at $532 \mathrm{~nm}$ and $600 \mathrm{~nm}$. The TBARS content was calculated using an extinction coefficient of $155 \mathrm{mM}^{-1} \mathrm{~cm}^{-1}$ based on fresh biomass.

\subsection{Statistical treatments}

All treatments were replicated three times. All concentrations were expressed on a dry weight basis except TBARS. Significant differences were determined by using one-way analysis of variance (ANOVA) and treatment means were compared by Tukey's multiple range tests at $\mathrm{p}<0.05$ was performed using JMP 10 PRO (SAS Institute Inc., Cary, NC, 1989-2010). Associations between variables were also assessed using Pearson's correlation coefficient.

\section{Results and discussion}

In our experiment, the effects of CrVI and sulfate on each other's uptake and translocation in $P$. vittata were tested by exposing $P$. vittata for $1 \mathrm{~d}$ in $0.2 \mathrm{X}$ Hoagland solutions (HS) containing $0.25 \mathrm{mM}$ sulfate and $0,0.5,2.5$ or $5.0 \mathrm{mM}$ CrVI or $0.1 \mathrm{mM} \mathrm{CrVI}$ and 0 , $0.25,1.25$ or $2.5 \mathrm{mM}$ sulfate. In addition, to evaluate CrIII uptake by PV, 1 d experiment with $0.1 \mathrm{mM}$ CrIII and 0 or $1.25 \mathrm{mM}$ sulfate was also carried out.

Exposing plants to high metal concentrations in hydroponics can be misleading if metals precipitate in solution and become unavailable to plants. Therefore, we calculated the solubility of $\mathrm{Cr}$ and sulfate in $0.2 \mathrm{X}$ HS at fixed $\mathrm{pH}$ using Visual MINTEQ 3 (Gustafsson, 2011). Even at the highest CrVI and sulfate concentrations, both elements were soluble for plant uptake. Predominant species in the solution included: $\mathrm{HCrO}_{4}^{-}$(74\%), and $\mathrm{Cr}_{2} \mathrm{O}_{7}^{-2}$ (24\%) for $\mathrm{CrVI}$, and $\mathrm{SO}_{4}^{2-}(81 \%), \mathrm{CaSO}_{4}^{+}(11 \%), \mathrm{KSO}_{4}^{+}(2.6 \%)$ and $\mathrm{MgSO}_{4}^{+}(4.4 \%)$ for sulfate.

\subsection{Sulfate enhanced Cr uptake and translocation by P. vittata}

CrVI was readily taken up by $P$. vittata roots, which was mainly retained in the roots with little translocation to the fronds. For example, at $\mathrm{CrVI}_{0.5}, \mathrm{Cr}$ concentrations were 52.2 and $6940 \mathrm{mg} \mathrm{kg}^{-1}$
$\mathrm{Cr}$ in $\mathrm{P}$. vittata fronds and roots (Fig. 1A), with 99\% of the $\mathrm{Cr}$ being accumulated in the roots. At $\mathrm{CrVI}_{2.5}$ and $\mathrm{CrVI}_{5.0}$, the fronds and roots $\mathrm{Cr}$ increased to 296-367 and $11,913-16,014 \mathrm{mg} \mathrm{kg}^{-1}$, respectively (Fig. 1A), again with $\mathrm{Cr}$ mainly being in the roots, similar to other plants. Shanker et al. (2005) speculated that $\mathrm{Cr}$ accumulation in the roots may be due to 1) $\mathrm{Cr}$ precipitation as insoluble salts, 2) immobilization with molecules such as sugar, pectins, celluloses, and hemicelluloses or 3) compartmentalization in the vacuoles of root cells. With increasing external $\mathrm{Cr}$ concentrations, $\mathrm{Cr}$ accumulation in the fronds increased 5.7-7 fold, which was more than the 1.7-2.3 fold for the roots, indicating limited $\mathrm{Cr}$ translocation from the roots to the fronds (Fig. $1 \mathrm{AB}$ ). Compared to solution $\mathrm{Cr}$ concentration at $0.5 \mathrm{mM}\left(26 \mathrm{mg} \mathrm{L}^{-1}\right)$, the root $\mathrm{Cr}$ concentration was 267-fold greater after 1 day uptake. The data indicated the amazing ability of $P$. vittata in $\mathrm{Cr}$ uptake at $289 \mathrm{mg} \mathrm{kg}^{-1} \mathrm{~h}^{-1}$.

To test if efficient $\mathrm{Cr}$ uptake is unique in $P$. vittata, we tested $\mathrm{Cr}$ uptake by fern plant $A$. capillus. Similar to $P$. vittata, $A$. capillus was efficient in taking up $\mathrm{CrVI}$, with corresponding $\mathrm{Cr}$ concentrations being $6,080,9050$ and $13,390 \mathrm{mg} \mathrm{kg}^{-1}$ in the roots at $\mathrm{CrVI}_{0.5}$, at $\mathrm{CrVI}_{2.5}$ and $\mathrm{CrVI}_{5.0}$, which were $14-32 \%$ less than those in $P$. vittata roots (Fig. 2A). Compared to the growth media, the amounts of $\mathrm{Cr}$ in plants roots were 51-267 fold greater than those in the media for both fern plants. It seemed that efficient $\mathrm{Cr}$ uptake also occurred in other fern plants. However, further study is needed to confirm this observation.

It is known that $\mathrm{Cr}$ negatively affects plant growth (Kabata-Pendias, 2011). There is no evidence that CrVI is essential for plant growth, although growth stimulation at low CrIII concentrations at $0.05-1 \mathrm{mg} \mathrm{L}^{-1}$ has been reported for some plants (Peralta-Videa et al., 2009). After $1 \mathrm{~d}$ exposure, $P$. vittata did not show sign of $\mathrm{Cr}$ toxicity in this study (data not shown). However, $\mathrm{Cr}$ toxicity was obvious under longer exposure of 2 weeks to $0.1 \mathrm{mM}$ CrVI, with $P$. vittata biomass being reduced from 3.37 to $1.34 \mathrm{~g}$, a $60 \%$ reduction (de Oliveira et al., 2014). The data suggested that CrVI is toxic to $P$. vittata at $>0.1 \mathrm{mM}\left(5.2 \mathrm{mg} \mathrm{L}^{-1}\right)$ under long term exposure. Compared to other plants, $P$. vittata plants were much more efficient in accumulating $\mathrm{Cr}$ in the roots (up to $16,014 \mathrm{mg} \mathrm{kg}^{-1}$, Fig. 1A). The reason for its high accumulation in the roots could be because CrVI is immobilized there, rendering it nontoxic to the plant. Since CrVI must cross the endodermis via symplast, CrVI was probably reduced to CrIII in $P$. vittata roots, which reduced its mobility from the roots to fronds and corresponded to its low translocation. It has been reported that CrIII bound with oxalate, citrate malate and acetate ligants in plants, inhibiting its translocation (Aldrich et al., 2003). Compared to other plants, the ability of $P$. vittata to concentrate $\mathrm{Cr}$ in the roots was extraordinary since $\mathrm{Cr}$ concentration in its roots was much higher than that reported for the most efficient $\mathrm{Cr}$-accumulator plants (de la Rosa et al., 2014; Schiavon et al., 2007). To determine if the $\mathrm{Cr}$ was accumulated on the roots surface, the roots were washed with $\mathrm{HNO}_{3}(1: 1 \mathrm{v} / \mathrm{v})$ for $20 \mathrm{~min}$. Most of the $\mathrm{Cr}$ was inside the roots (89-98\%) (data not shown).

It is possible that plants passively take up large amounts of $\mathrm{CrVI}$ at phytotoxic levels through broken cell membranes. For example, CrVI causes plasmolysis in peripheral cells on root surfaces of bush beans (Aldrich et al., 2003). Thiobarbituric acid reacting substances (TBARS) have been used to indicate metabolic stress caused by metals including Cr (Ercal et al., 2001). It is an indicator of free radical formation in the tissues and is used as an index of lipid peroxidation in plants (Hartley-Whitaker et al., 2001). In the absence of $\mathrm{Cr}$, the TBARS in $P$. vittata fronds were $9.44 \mu \mathrm{mol} \mathrm{g}^{-1} \mathrm{fw}$ (Fig. 1C). With increasing external CrVI concentrations, TBARS increased to $23.7-58.8 \mu \mathrm{mol} \mathrm{g}^{-1}$ fw. The increase in TBARS was $150-522 \%$ in the fronds, a clear indication of oxidative stress in $P$. vittata plants. The increased concentrations of TBARS in the 

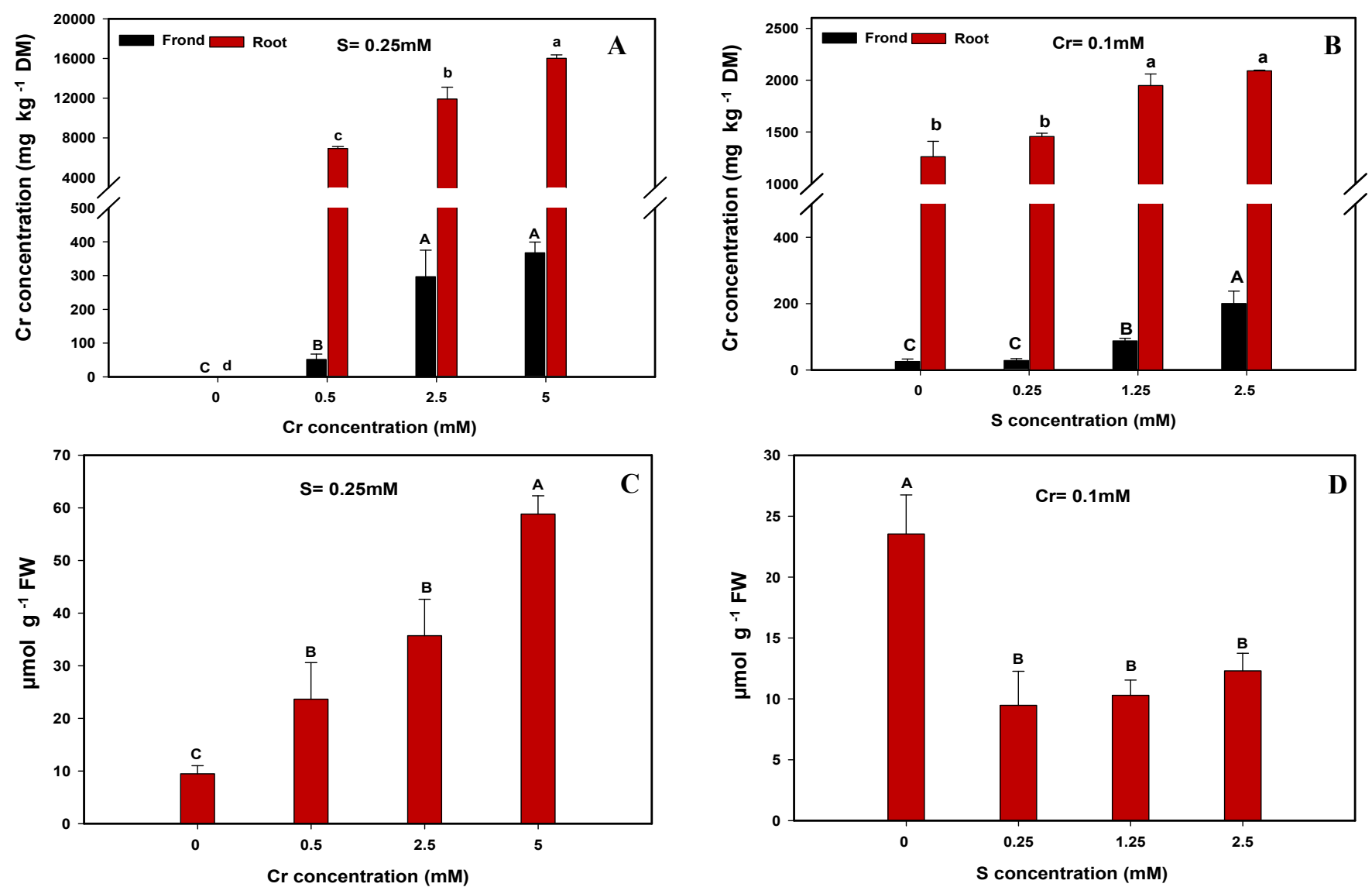

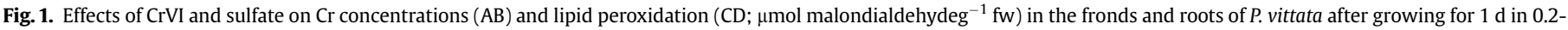

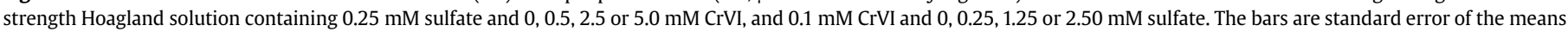
of three replicates. Treatments followed by the same letters are not significantly different at $\alpha=0.05$.

biomass indicated lipid peroxidation of cell membranes in plants caused by oxidative stress (Flora, 2011). This is because production of reactive oxygen species results in the blockage or inactivation of various enzymes and functional groups that regulate the normal functioning of plants (La Rocca et al., 2009). However, addition of 0.25-2.5 mM sulfate decreased TBARS concentration from 23.5 to $9.46-12.3 \mu \mathrm{mol} \mathrm{g}^{-1} \mathrm{fw}$, indicating that sulfate alleviated $\mathrm{Cr}$-induced oxidation stress in P. vittata fronds (Fig. 1D).

It was unclear why addition of sulfate increased $\mathrm{Cr}$ uptake by $P$. vittata. At $0.1 \mathrm{mM} \mathrm{CrVI}, P$. vittata averaged 25.7 and $1261 \mathrm{mg} \mathrm{kg}^{-1}$ $\mathrm{Cr}$ in the fronds and roots, with $98 \%$ of the $\mathrm{Cr}$ being in the roots (Fig. 1B). At $0.1 \mathrm{mM} \mathrm{CrVI}$ and $0.25 \mathrm{mM} \mathrm{S}$, P. vittata accumulated 28.8 and $1457 \mathrm{mg} \mathrm{kg}^{-1} \mathrm{Cr}$ in the fronds and roots, respectively (Fig. 1B). As external sulfate concentration increased from 2.5 to $5.0 \mathrm{mM}, \mathrm{Cr}$ in $P$. vittata roots increased from 1947 to $2090 \mathrm{mg} \mathrm{kg}^{-1}$ (Fig. 1B). However, $\mathrm{Cr}$ concentrations in the fronds increased only slightly from 87.7 to $200 \mathrm{mg} \mathrm{kg}^{-1} \mathrm{Cr}$. We demonstrated that the addition of sulfate to the growth media significantly increased $\mathrm{Cr}$ uptake by $P$. vittata, with the increase occurring mostly in the roots.

CrVI is taken up by some plants via sulfate or phosphate transporters (Shiavon et al., 2012; de Oliveira et al., 2015; Shardendu, 2013; Qian et al., 2013). Schiavon et al. (2007) tested the impact of sulfate on CrVI or phosphate uptake in maize plants. After 2 day exposure, they found that CrVI inhibits sulfate uptake but not phosphate uptake. The fact that sulfate at $1.25-2.5 \mathrm{mM}$, which was 12.5-25 times greater than CrVI at $0.1 \mathrm{mM}$, enhanced $\mathrm{Cr}$ uptake in P. vittata by $1.3-7.8$ fold (Fig. 1B) may suggest that $\mathrm{Cr}$ didn't not share the same transporters with sulfate in $P$. vittata, which is different from other plants (Schiavon et al., 2012). Kim et al. (2006) reported that the overexpression of putative yeast transcriptional activators MSN1 and NtST1 (Nicotiana tabacum sulfate transporter 1) enhanced $\mathrm{Cr}$ and sulfate accumulation in transgenic tobacco. These researchers suggested that both sulfate and CrVI are taken up via sulfate transporters in plants. However, de la Rosa et al. (2014), working with Helianthus annuus seedlings in hydroponics solution containing $0.19 \mathrm{mM} \mathrm{CrVI}$ and $1 \mathrm{mM}$ sulfate, found that after 15 days of exposure, sulfate increased $\mathrm{Cr}$ accumulation in the roots by $29 \%$ and in the shoots by $66 \%$ compared to control. The authors attributed that it may be possible that plant age plays a role in the amount of expressed sulfate transporters. de Oliveira et al. (2014) found that, after 1 week exposure to $0.05 \mathrm{mM}$ CrVI and $1.25 \mathrm{mM}$ sulfate, sulfate increased $\mathrm{Cr}$ concentration by 4 -fold to $841 \mathrm{mg} \mathrm{kg}^{-1}$ in the fronds and 3-fold to $14,473 \mathrm{mg} \mathrm{kg}^{-1}$ in the roots compared to the control. In the present study, addition of sulfate to $P$. vittata plants increased $\mathrm{Cr}$ uptake in the roots and fronds besides alleviation of $\mathrm{Cr}$-induced oxidative stress (Fig. 1AB).

\subsection{CrVI was reduced to CrIII in the roots of P. vittata}

To better understand the impact of $\mathrm{Cr}$ on plant uptake, it is important to know their speciation. After 1 day exposure, $\mathrm{Cr}$ speciation in $P$. vittata growth media containing $0.25 \mathrm{mM}$ sulfate and $0.1,2.5$ or $5.0 \mathrm{mM} \mathrm{CrVI} \mathrm{revealed} \mathrm{limited} \mathrm{CrVI} \mathrm{reduction} \mathrm{(7-11 \% )}$ (Fig. 3A), indicating that most of the $\mathrm{Cr}$ taken up by P. vittata was CrVI (93-89\%). These results are in agreement with McGrath (1982) who showed that, after culturing oat plants for 4 weeks, 

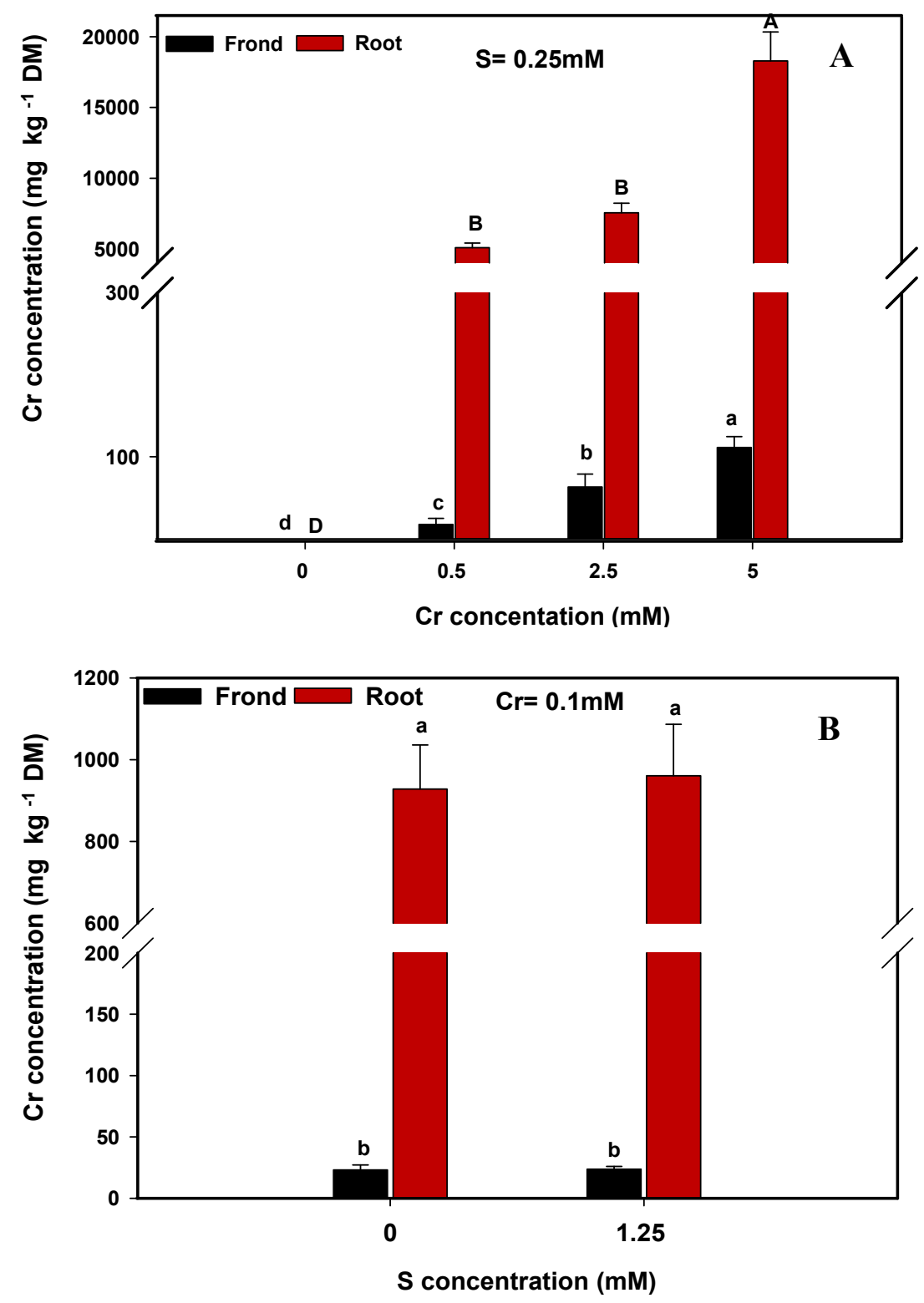

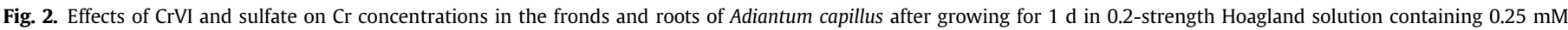

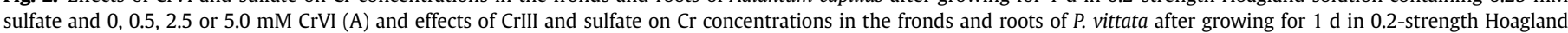

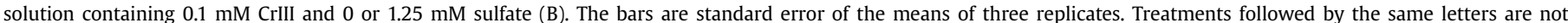
significantly different at $\alpha=0.05$.

$\mathrm{Cr}$ species remain unchanged in the nutrient solution containing CrIII or CrVI.

In addition to $\mathrm{Cr}$ speciation in growth media, we also determined $\mathrm{Cr}$ speciation in the biomass. Though the plants were primarily exposed to CrVI, CrIII was the main form in P. vittata roots, i.e., the solution was dominated by CrVI (89-93\%; Fig. 3A), but $P$. vittata roots were dominated by CrIII (89-96\%; Fig. 3B). At 0.5-5.0 $\mathrm{mM} \mathrm{Cr}, \quad P$. vittata accumulated $52-367$ and $6940-16,015 \mathrm{mg} \mathrm{kg}^{-1}$ of $\mathrm{Cr}$ in the fronds and roots, with $64-78 \%$ and $89-96 \%$ of the $\mathrm{Cr}$ as CrIII in the fronds and roots, respectively (Fig. 3B). The low amounts of CrVI in the roots suggested that $P$. vittata probably reduced toxic CrVI to relatively nontoxic CrIII. It was possible that CrVI was reduced to CrIII on the root surface by $P$. vittata, which is rich in microorganism (Cheung and Gu, 2007). It was also possible that CrVI was reduced to CrIII in the rhizomes similar to As (Mathews et al., 2010). Since the rhizomes were not separated from the roots in this study, further research is needed to identify the tissue location and nature of CrVI reduction.

Reduction of CrVI to the less toxic and less mobile CrIII is probably an important step in $\mathrm{Cr}$ detoxification in plants including $P$. vittata. Some plants have the ability to reduce $\mathrm{CrVI}$ to $\mathrm{CrIII}$ in the roots (Santana et al., 2012). In P. vittata roots, 89-93\% of the $\mathrm{Cr}$ was present as CrIII compared to $64-78 \%$ in the fronds (Fig. 3B). In other words, much higher amount of CrVI was translocated to the fronds compared to CrIII. This was probably because CrVI was more soluble than CrIII. This hypothesis was tested by shaking $0.5 \mathrm{~g}$ of $P$. vittata roots with $10 \mathrm{~mL}$ DI water for $2 \mathrm{~h}$, though the roots were dominated by CrIII, 93-96\% of the $\mathrm{Cr}$ in the solution was $\mathrm{CrVI}$ (Fig. 3C). As little CrIII was detected in the solution, the data suggested that CrIII in the roots was insoluble. 

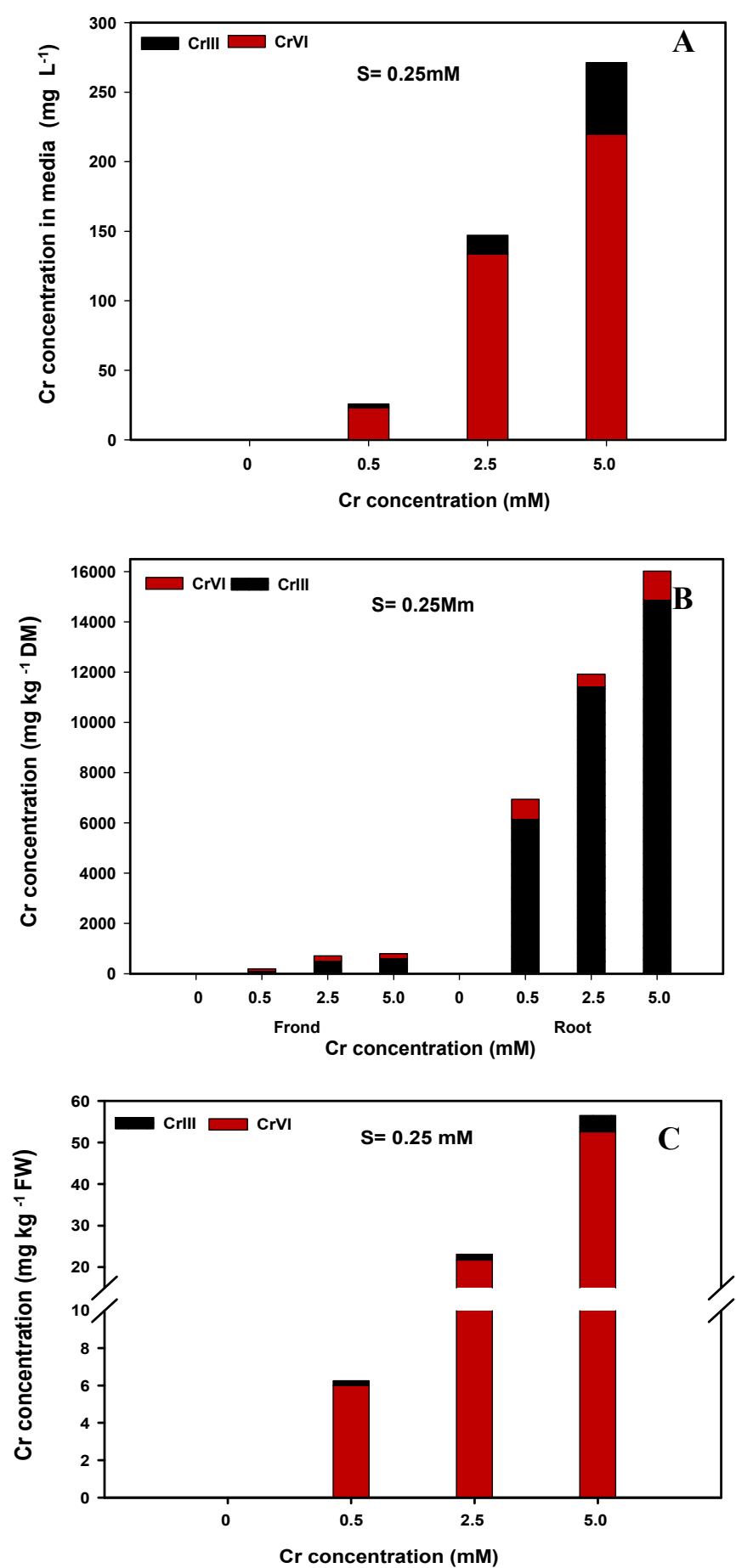

Fig. 3. Cr speciation in 0.2-strength Hoagland solution (HS) (A), in the fronds and roots of $P$. vittata (B), and in solution after shaking $0.5 \mathrm{~g}$ of $P$. vittata roots with $10 \mathrm{~mL}$ DI water for $2 \mathrm{~h}$ (C). P. vittata was grown for $1 \mathrm{~d}$ in 0.2 -strength $\mathrm{HS}$ containing $0.25 \mathrm{mM} \mathrm{S}$ and 0 , $0.5,2.5$ or $5.0 \mathrm{mM}$ CrVI. The bars are standard error of the means of three replicates. Treatments followed by the same letters are not significantly different at $\alpha=0.05$.

To compare $P$. vittata uptake of CrVI with CrIII, we evaluated CrIII uptake by $P$. vittata after 1 day growth in 0.2 X HS. At CrIII $_{0.1}$, $P$. vittata accumulated $928 \mathrm{mg} \mathrm{kg}{ }^{-1} \mathrm{Cr}$ in the roots and in the presence of $1.25 \mathrm{mM}$ sulfate, $\mathrm{Cr}$ concentration was $960 \mathrm{mg} \mathrm{kg}^{-1}$ in the roots (Fig. 2B). In comparison, at $\mathrm{CrVI}_{0.1}, P$. vittata accumulated $1261 \mathrm{mg} \mathrm{kg}^{-1}$ in the roots (Fig. 1B). The data indicated that $P$. vittata was much more efficient in taking up CrVI than CrIII, resulting in 1.4-fold higher Cr uptake with CrVI than CrIII (Figs. 1B and 2B). Sulfate did not affect CrIII uptake, indicating that CrIII did not depend on metabolic energy to be taken up by P. vittata, which is in agreement with previous experiments (Shanker et al., 2005). The fact that the growth solution was dominated by CrVI (89-93\%) and $P$. vittata was more efficient in taking up CrVI suggested that CrVI was taken up by $P$. vittata and was probably reduced in the roots. At $\mathrm{CrVI}_{2.5}$, P. vittata accumulated $74 \%$ and $96 \%$ of CrIII in the fronds and roots respectively (Fig. 3B), which was consistent with $\mathrm{Cr}_{2} \mathrm{O}_{3}$ (chromium oxide) being detected in the roots using X-ray diffraction (data not shown). Similar results were reported in sunflower (H. annuus) (de la Rosa et al., 2014) who determined Cr speciation in the roots using micro XRF after exposing the plant to CrVI and sulfate in hydroponics ( $0.19 \mathrm{mM}$ CrVI and $0,0.1,1$ or $10 \mathrm{mM}$ sulfate). They revealed that CrVI is rapidly reduced to CrIII in the roots and $80 \%$ is precipitated as CrIII phosphate. Considering CrVI concentrations in contaminated water are within the range in the present study (0.1-5.0 mM) (EPA, 1990), P. vittata not only removed CrVI from solution ( $289 \mathrm{mg} \mathrm{kg}^{-1} \mathrm{~h}^{-1}$ ), but also decreased $\mathrm{Cr}$ toxicity by reducing $\mathrm{CrVI}$ to $\mathrm{CrIII}$, suggesting that $P$. vittata may have potential to remove $\mathrm{Cr}$ from contaminated water.

\subsection{Addition of CrVI increased $S$ concentrations in P. vittata}

Sulfur requirement for optimal plant growth varies from 1000 to $5000 \mathrm{mg} \mathrm{kg}^{-1}$ in plants (Marschner, 2012). The sulfate concentrations in $P$. vittata fronds and roots were within the range reported for $P$. vittata plants (Wei et al., 2010). In the presence of $0.25 \mathrm{mM}$ sulfate, sulfur concentration in P. vittata fronds and roots were 2176 and $1166 \mathrm{mg} \mathrm{kg}^{-1}$, with 1.9 times more sulfur being in the fronds than in the roots (Fig. 4A). Sulfur translocation to the fronds is typical for macronutrients in plants, with more being in aerial parts. However, it was unclear why increasing CrVI concentration in the solution increased fronds and roots $\mathrm{S}$ concentration in $P$. vittata $(\mathrm{p}<0.05)$. For example, at 2.5-5.0 mM CrVI, S concentrations were increased by $29-10 \%$ from 2176 to $2399-2798 \mathrm{mg} \mathrm{kg}^{-1}$ in the fronds and by $36-57 \%$ from 1165 to $1836-1585 \mathrm{mg} \mathrm{kg}^{-1}$ in the roots (Fig. 4B). P. vittata was effective in translocating sulfur in the presence of $\mathrm{Cr}$, with most of the sulfur in the fronds (Fig. 4B), suggesting that $P$. vittata probably took up more sulfur in respond to $\mathrm{Cr}$ accumulation. In other words, sulfur uptake in $P$. vittata corresponded to $\mathrm{Cr}$ uptake rather than on the sulfate level in the medium (Fig. 4AB). The fact that CrVI did not decrease sulfur concentrations in $P$. vittata (Fig. 1AB) may be because sulfur was taken up by $P$. vittata more rapidly than CrVI by the roots. The fact that CrVI did not affect sulfur concentrations suggested that sulfate probably did not compete with CrVI uptake and translocation or $P$. vittata possessed unique sulfate transporters that did not compete with CrVI uptake. Different sulfate transporters have different functions since they differ in the affinity for ions (Pilsyk and Paszewski, 2009). CrVI uptake by plant roots occurs by active transport, but there is no conclusive information about its translocation mechanisms (Shanker et al., 2009). In contrast to our results, after exposing Citrullus vulgaris to different CrVI concentrations, Dube et al. (2003) found that sulfate decreased in the leaves at all $\mathrm{Cr}$ levels.

Since $\mathrm{CrVI}$ was supplied as $\mathrm{K}_{2} \mathrm{Cr}_{2} \mathrm{O}_{7}$ in this experiment, the beneficial effect of $\mathrm{Cr}$ on sulfate uptake was probably from additional $\mathrm{K}$ in the solution. $\mathrm{K}$ serves as a dominant cation for counterbalancing anions in plants (Marschner, 2012). At higher $\mathrm{Cr}$ levels, enhanced $\mathrm{Cr}$ uptake in $\mathrm{P}$. vittata caused increasing plant $\mathrm{K}$ concentrations, probably to balance excessive anions $\mathrm{Cr}$ (Fig. 4C). K concentration in the fronds and roots were increased with increasing $\mathrm{Cr}$ concentration in the media by $17-39 \%$ in the fronds (Fig. $4 \mathrm{C}$ ).

The addition of sulfate in the growth media containing CrVI did not change sulfur concentration in the fronds and roots of $P$. vittata 

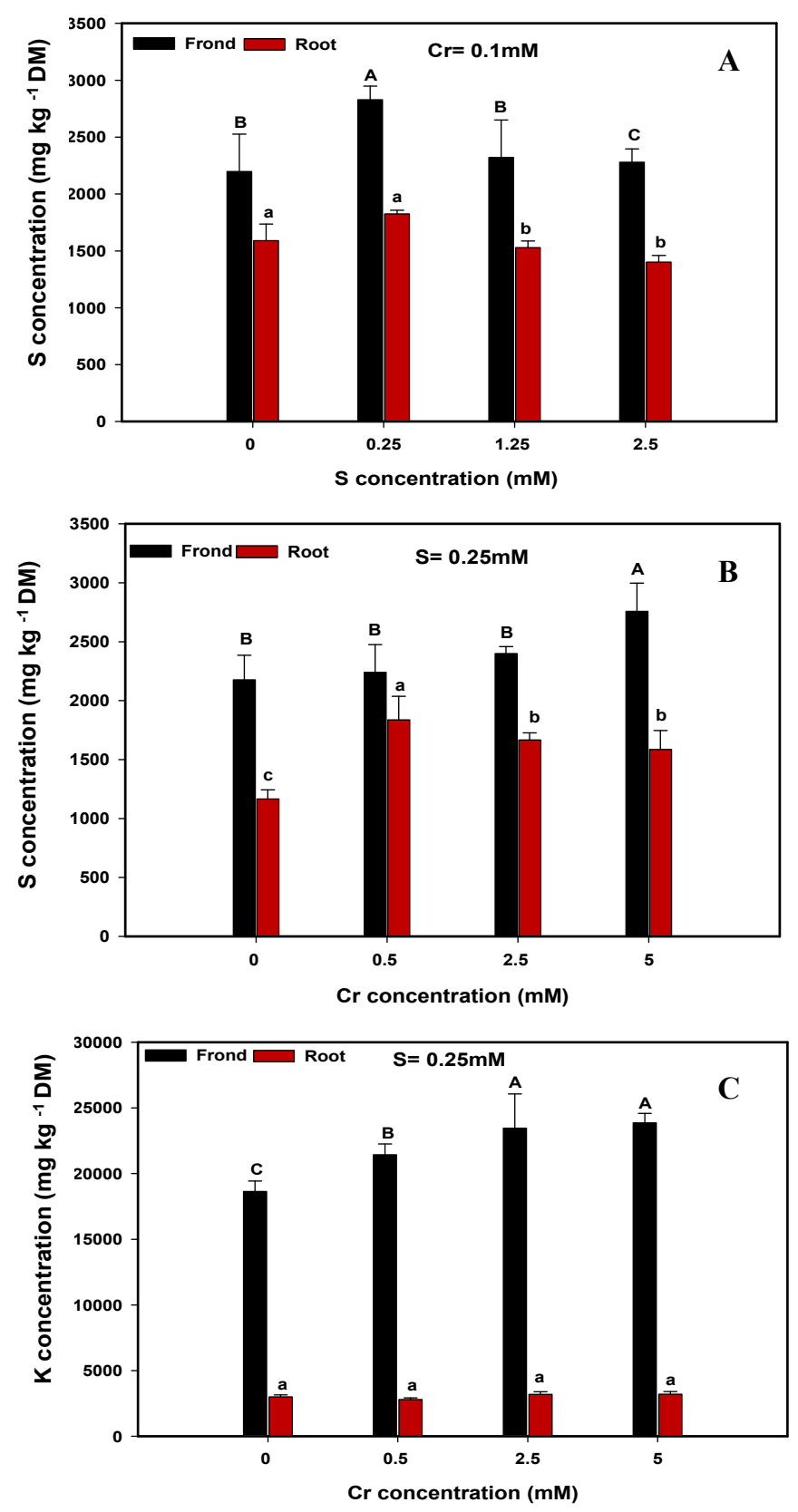

Fig. 4. Effects of $\mathrm{CrVI}$ and sulfate on sulfur $(\mathrm{AB})$ or $\mathrm{K}(\mathrm{C})$ concentrations in the fronds and roots of $P$. vittata after growing for $1 \mathrm{~d}$ in 0.2 -strength Hoagland solution containing $0.1 \mathrm{mM} \mathrm{CrVI}$ and $0,0.25,1.25$ or $2.5 \mathrm{mM}$ sulfate $(\mathrm{A})$ and $0.25 \mathrm{mM} \mathrm{S}$ and $0,0.5,2.5$ or $5.0 \mathrm{mM} \mathrm{CrVI}$ (B and C). The bars are standard error of the means of three replicates. Treatments followed by the same letters are not significantly different at $\alpha=0.05$.

(Fig. 4A). For example, as sulfate concentrations in the media increased from 0.25 to $2.5 \mathrm{mM}$, the sulfur concentrations increased from 2197 to $2278 \mathrm{mg} \mathrm{kg}^{-1}$ in the fronds, but decreased from 1589 to $1400 \mathrm{mg} \mathrm{kg}^{-1}$ in the roots. The results indicated that the addition of $\mathrm{Cr}$ probably induced stress in $\mathrm{P}$. vittata, limiting sulfate uptake. Due to its structural similarity with essential nutrient sulfate, $\mathrm{CrVI}$ affects plant nutrition by interfering its uptake and translocation (Shiavon et al., 2007, 2012). In the case of $P$. vittata, our results showed that CrVI increased sulfate uptake and translocation at all CrVI levels (Fig. 4B). Similar effect was observed in $P$. vittata with arsenate and sulfate where sulfate uptake in $P$. vittata roots was increased with increasing As concentration in hydroponics (Wei et al., 2010). They found that $15-30 \mathrm{mg} \mathrm{L}^{-1}$ of sulfate enhanced
P. vittata As uptake by $18-85 \%$. In the present study, CrVI and sulfate helped each other in uptake and translocation by $P$. vittata, suggesting that CrVI probably did not share the same transporters with sulfate in P. vittata.

\section{Conclusion}

Though $\mathrm{Cr}$ generally inhibits the growth and development of most non-tolerant plants, our results showed that $P$. vittata tolerated $5.0 \mathrm{mM} \mathrm{CrVI}\left(260 \mathrm{mgL}^{-1}\right)$ in the presence of sulfate. $P$. vittata was effective in taking up $\mathrm{Cr}$, but not effective in translocating $\mathrm{Cr}$ to the fronds as most of the $\mathrm{Cr}$ was concentrated in the roots. While CrVI was provided in the media, 89-93\% and 78-96\% CrIII was found in P. vittata fronds and roots. Reduction of CrVI to CrIII in plants could be one of its detoxification mechanisms. Addition of sulfate increased $\mathrm{Cr}$ accumulation in $P$. vittata roots whereas addition of CrVI increased sulfate uptake by $P$. vittata. These results indicated that $P$. vittata had potential in $\mathrm{Cr}$ phytoremediation in contaminated sites but further studies are needed to evaluate this potential. However, the mechanisms of how sulfate and CrVI enhance each other's accumulation in $P$. vittata need further investigation.

\section{Acknowledgments}

This research is supported in part by the University of Florida and the CAPES-Brazilian governmental organizations for scholarship (No. 185313-9)received by the senior author.

\section{References}

Aldrich, M.V., Gardea-Torresdey, J.L., Peralta-Videa, J.R., Parsons, J.G., 2003. Uptake and reduction of CrVI to CrIII by mesquite (Prospis spp.): chromate-plant interaction in hydroponics and solid media studied using XAS. Environ. Sci. Technol. 37, 1859-1864.

Agency for Toxic Substances and Disease Registry (ATSDR), 2012. Health and Human Services (Atlanta, GA.).

Cheung, K.H., Gu, J.D., 2007. Mechanism of hexavalent chromium detoxification by microorganisms and bioremediation application potential: a review. Int. Biodeterior. Biodegrad. 59, 8-15.

de la Rosa, G., Castillo-Michel, H., Cruz-Jiménez, G., Bernal-Alvarado, J., CórdovaFraga, López-Moreno, L., Cotte, M., 2014. Cr localization and speciation in roots of chromate fed Helianthus annuus L. seedlings using synchrotron techniques techniques. Int. J. Phytoremed. 16, 7-12.

de Oliveira, L.M., Ma, L.Q., Santos, J.A.G., Guilherme, L.R.G., Lessl, J.T., 2014. Effects of arsenate, chromate, and sulfate on arsenic and chromium uptake and translocation by arsenic hyperaccumulator Pteris vittata L. Environ. Pollut. 184, 187-192.

de Oliveira, L.M., Lessl, J.T., Gress, J., Tisarum, R., Guilherme, L.R.G., Ma, L.Q., 2015. Chromate and phosphate inhibited each other's uptake and translocation in arsenic hyperaccumulator Pteris vittata L. Environ. Pollut. 197, 240-246.

Dimitroula, H., Syranidou, E., Manousaki, E., Nikolaidis, N.P., Karatzas, G.P. Kalogerakis, N., 2015. Mitigation measures for chromium-VI contaminated groundwater - The role of endophytic bacteria in rhizofiltration. J. Hazard. Mater 281, 114-120.

Dube, B.K., Tewari, K., Chatterjee, J., Chatterjee, C., 2003. Excess chromium alters uptake and translocation of certain nutrients in citrullus. Chemosphere 53 1147-1153.

Eaton, A.D., Clesceri, L.S., Greenberg, A.E., 1995. Standard methods for the examination of water and wastewater. In: American Public Health Association (APHA). AWWA, WPCF, Washington, DC, pp. 225-257.

EPA (Environmental Protection Agency), 1990. Environmental Pollution Control Alternatives. EPA/625/5-90/025, EPA/625/4-89/023 (Cincinnati, US).

Ercal, N., Guer-Orhan, H., Aykin-Burns, N., 2001. Toxic metals and oxidative stress part I: mechanisms involved in metal induced oxidate damage. Curr. Topics Med. Chem. 1, 529-539.

Flora, S.J.S., 2011. Arsenic-induced oxidative stress and its reversibility. Free Radical. Biol. Med. 51, 257-281.

Groppa, M.D., Tomara, M.L., Benavides, M.P., 2001. Polyamines as protectors against cadmium or copper-induced oxidative damage in sunflower leaf discs. Plant Sci. $161,481-488$.

Gustafsson, J.P., 2011. Visual MINTEQ Ver. 3.0 KTH. Department of Land and Water Resources Engineering. http://www2.lwr.kth.se/English/OurSoftware/vminteq/.

Hartley-Whitaker, J., Ainsworth, G., Meharg, A.A., 2001. Copper- and arsenateinduced oxidative stress in Holcus lanatus L. clones with differential sensitivity. 
Plant Cell Environ. 24, 713-722.

Kabata Pendias, A., 2011. Trace Elements in Soils and Plants, fourth ed. CRC, Boca Raton, p. 534.

Kalve, S., Sarangi, B.K., Pandey, R.A., Chakrabarti, T., 2011. Arsenic and chromium hyperaccumulation by an ecotype of Pteris vittata - prospective for phytoextraction from contaminated water and soil. Curr. Sci. 100, 888-894.

Khakhathi, L., Mandiwana, K., Panichev, N., Panicheva, S., 2011. Determination of chromium (VI) in black, green and herbal teas. Food Chem. 129, 1839-1843.

Kim, Y.J., Kim, J.H., Lee, C.E., 2006. Expression of yeast transcriptional activator MSN1 promotes accumulation of chromium and sulfur by enhancing sulfate transporter level in plants. FEBS Lett. 580, 206-210.

Kleiman, I.D., Cogliatti, D.H., 1997. Uptake of chromate in sulfate deprived wheat plants. Environ. Pollut. 97, 131-135.

Kristine, L.W., Stout, M.D., Herbert, R.A., Travlos, G.S., Kissling, G.E., Collins, B.J., Hooth, M.J., 2013. Mechanistic insights from the NTP studies of chromium. Toxicol. Pathol. 41, 326-342.

La Rocca, N., Andreoli, C., Giacometti, G.M., Rascio, N., Moro, I., 2009. Responses of the Antarctic microalga Koliella antarctica (Trebouxiophyceae, Chlorophyta) to cadmium contamination. Photosynthetica 47, 471-479.

López-Bucio, J.S., Dubrovsky, J.G., Raya-González, J., Ugartechea-Chirino, Y., LópezBucio, J., Luna-Valdez, L.A., De Ramos-Vega, M., León, P., Guevara-García, A.A. 2014. Arabidopsis thaliana mitogen-activated protein kinase 6 is involved in seed formation and modulation of primary and lateral root development. J. Exp. Bot. 65, 169-183.

Ma, L.Q., Komar, K.M., Tu, C., Zhang, W., Cai, Y., Kennelley, E.D., 2001. A fern that hyperaccumulates arsenic. Nature 409, 579 .

Marschner, H., 2012. Mineral Nutrition of Higher Plants. Academic Press, San Diego.

Mathews, S., Ma, L.Q., Rathinasabapathi, B., Natarajan, S., Saha, U.K., 2010. Arsenic transformation in the growth media and biomass of hyperaccumulator Pteris vittata L. Bioresour. Technol. 101, 8024-8030.

McGrath, S.P., 1982. The uptake and translocation of tri-and-hexavalent chromium and effects on the growth of oat in flowing nutrient solution and soil. New. Phytol. 92, 381-390.

Oliveira, H., 2012. Chromium as an environmental pollutant: insights on induced plant toxicity. J. Bot. 3, 1-8.

Peralta-Videa, J.R., Lopez, M.L., Narayan, M., Saupe, G., Gardea-Torresdey, J., 2009 The biochemistry of environmental heavy metal uptake by plants: implications for the food chain. Int. J. Biochem. Cell. Biol. 41, 1665-1677.

Pilsyk, S., Paszewski, A., 2009. Sulfate permeases - phylogenetic diversity of sulfate transport. Acta Biochim. Pol. 56, 375-384.
Qian, H., Sun, Z., Sun, L., Jiang, Y., Wei, Y., Xie, J., Fu, Z., 2013. Phosphorus availability changes chromium toxicity in the freshwater alga Chlorella vulgari. Chemosphere 93, 885-889.

Ramírez-Díaz, M.I., Díaz-Pérez, C., Vargas, E., Riveros-Rosas, H., Campos-García, J., Cervantes, C., 2008. Mechanisms of bacterial resistance to chromium compounds. Biometals 21, 321-332.

Santana, K.B., Almeida, A.A.F., Sousa, V.L., Mangaeira, P.A.O., Silva, D.C.S., Gomes, F.P., Dutruch, L., Loguercio, L.L., 2012. Physiological analyses of Genipa americana reveals a tree with ability as phytostabilizer and rhizofilter of chromium ions for phytoremediation of polluted watersheds. Environ. Exp. Bot. 80, 35-42.

Schiavon, M., Wirtz, M., Borsa, P., Quaggiotti, S., Hell, R., Malagoli, M., 2007. Chromate differentially affects the expression of a high-affinity sulfate transporter and isoforms of components of the sulfate assimilatory pathway in Zea mays (L.). Plant Biol. 9, 662-671.

Schiavon, M., Gallaa, G., Wirtz, M., Pilon-Smits, E.A.H., Telatina, V., Quaggiotti, S., Hell, R., Barcacciaa, G., Malagoli, M., 2012. Transcriptome profiling of genes differentially modulated by sulfur and chromium identifies potential targets for phytoremediation and reveals a complex $\mathrm{S}-\mathrm{Cr}$ interplay on sulfate transport regulation in B. juncea. J. Hazard. Mater 15, 192-200.

Shanker, A.K., Cervantes, C., Loza-Tavera, H., Avudainayagam, S., 2005. Chromium toxicity in plants. Environ. Int. 31, 739-753.

Shanker, A.K., Djanaguiraman, M., Venkateswarlu, B., 2009. Chromium interactions in plants: current status and future strategies. Metallomics 1, 375-383.

Shardendu, D.S., 2013. Amendment in phosphorus levels moderate the chromium toxicity in Raphanus sativus L. as assayed by antioxidant enzymes activities. Ecotoxicol. Environ. Saf. 95, 161-170.

Sridhar, B.B.M., Han, F.X., Diehl, S.V., Monts, D.L., Su, Y., 2011. Effect of phytoaccumulation of arsenic and chromium on structural and ultrastructural changes of brake fern (Pteris vittata). Braz. J. Plant Physiol. 23, 285-293.

USEPA- US Environmental Protection Agency, 1995, Method 3060A: Alkaline digestion of hexavalent chromium, Test Methods for Evaluating Solid Waste, Physical/Chemical Methods - SW-846. U.S. Environmental Protection Agency, Washington, DC.

Wei, S., Ma, L.Q., Saha, U., Mathews, S., Sundaram, S., Rathinasabapathi, B., Zhou, Q., 2010. Sulfate and glutathione enhanced arsenic accumulation by arsenic hyperaccumulator Pteris vittata L. Environ. Pollut. 158, 1530-1535.

Zakaria, Z.A., Zakaria, Z., Surif, S., Ahmad, W.A., 2007. Hexavalent chromium reduction by Acinetobacter haemolyticus isolated from heavy-metal contaminated wastewater. J. Hazard. Mater 146, 30-38. 